\title{
REGISTRATION OF BIOLOGICAL PESTICIDES: A REGULATOR'S VIEW POINT
}

\author{
W. HUGHES \\ Agricultural Compounds Unit, Ministry of Agriculture \\ P O Box 40-063, Upper Hutt
}

\begin{abstract}
Biological pesticides require registration under the Pesticides Act 1979. Such agents were declared pesticides by an Order in Council in 1984. Specific registration guidelines were developed for them as it was recognised that such products would require different types of data from those required for chemical-based pesticides. To date only a small number of biological pesticides have been registered in New Zealand. Their development has been hindered by a number of factors such as development costs, regulatory requirements and user acceptance.
\end{abstract}

Keywords: registration, biopesticide, regulatory

\section{INTRODUCTION}

The Pesticides Act 1979 (Act) requires a pesticide to either be registered or have an Experimental Use Permit (EUP) before it can be sold or imported into New Zealand. An Order in Council made by the Governor-General in August 1984 declared certain biological pesticides to be pesticides under the Act. This order defined biological pesticides to be microbial pathogens, including bacteria, protozoa, rickettsia, fungi, nematodes and viruses or the mutants of any of these agents, intended for sale to control invertebrate pests, weeds or microbial pathogens of crops. Biological pesticides that are also genetically modified organisms require approval by the Interim Committee on Novel Genetic Techniques prior to the company applying for its registration under the Act. In addition, biological pesticides imported into New Zealand may also require approval from the Ministry of Agriculture. This approval is required prior to the Agricultural Compounds Unit (ACU) processing applications (EUPs or full registrations) of these products. It should be remembered that the Act only covers products which are packaged, and sold. Therefore, inundative release of biological pesticides are not be covered by the Act. However, such releases are covered by other Acts and Regulations.

New legislation is being developed to control pesticides in the future. The two pieces of legislation are- the Hazardous Substances and New Organisms Act and the Agricultural Compounds and Veterinary Medicines Bill. Methodology, standards and criteria have yet to be finalised on how both will handle biological pesticides. Once enacted, the Pesticides Act 1979 will be repealed along with a number of Acts and Regulations.

\section{REGISTRATION REQUIREMENTS}

The Pesticides Board recognised that biological pesticides would require registration and that the data requirements for such products would differ from those used for chemical-based pesticides. In the early 1980s, the Pesticides Section developed guidelines based on the UK guidelines. In 1982, an ad hoc working party consisting mainly of personnel from Government Departments was formed to consider these registration guidelines. The draft guidelines were also circulated to a range of organisations for their input.

The final guidelines cover identification, toxicological data, residue data, environmental data, efficacy data and biological properties of biological pesticides. The data requirements vary depending on the type of clearance required, whether it be for limited trial work under an Experimental Use Permit (EUP) or full commercialisation under registration. A brief summary of requirements (Pesticides Section 1984) is 
provided as follows:

a Identification-information on taxonomy of the biological pesticide for identification covering systematic name and strain, tests and criteria used for identification; composition of the unformulated material.

b Toxicological Data - a three tier safety testing system is used. Information from the usual toxicity studies is required e.g. acute studies. In addition, information on infectivity of the living agent, multiplicationin vivo, and its allergenic potential may also be required. The first tier testing covers the technical material (ie unformulated) and includes oral, respiratory, intraperitoneal, eye and dermal exposure studies along with allergenicity, hypersensitivity and mutagenicity studies. Should these studies be 'negative', studies under the second and third tiers are not required. The assessment of studies from higher tier testing can mean the product may have restrictions placed on its use or be rejected. The tier system is slightly different when considering viruses as pathogenicity of viruses is associated with their infectivity, rather than toxins.

c Residue Data-identification and measurement of residues may be required on edible crops at harvest or in grazing animals following the use of biological pesticides. Consideration of multiplication in or on animals, crops or food is also required.

d Environmental Data - information required covers a review of existing general knowledge describing the expected effects on the environment and its biota. This provides the basis for the decision on whether further data are required. Testing may be required on both non-target invertebrates and vertebrates and would, in most cases, include infectivity studies.

e Efficacy Data - information required is similar to that required for chemical-based pesticides i.e. quantitative trial work demonstrating the efficacy of the product.

f Biological Properties - information on spectrum of activity, specificity etc under different environmental and geographical situations.

The guidelines are used in conjunction with the Board's procedures for registration of pesticides such as labelling requirements, forms etc.

\section{NEW ZEALAND SITUATION}

At the 1st of March 1997, there were 873 registered pesticides, of which $12(1.4 \%)$ were biological pesticides. These biological pesticides utilize nine different active ingredients out of a total of 305 (3.0\%). Table 1 shows the number of applications (EUPs and full registration) of non-biological pesticides versus biological pesticides received by the Board over the 1991 to 1996 period.

TABLE 1: Number of applications (EUP and Registration) received by the ACU for biological and non-biological pesticides, 1991 to 1996.

\begin{tabular}{ccc}
\hline Year & BiologicalPesticides & Non-BiologicalPesticides \\
\hline 1991 & 4 & 108 \\
1992 & 6 & 143 \\
1993 & 5 & 125 \\
1994 & 5 & 107 \\
1995 & 9 & 128 \\
1996 & 6 & 175 \\
\hline
\end{tabular}

The proportion of imported versus locally manufactured biological pesticides registered is fairly even. However, the majority of applications are for overseas developed biological pesticides. These figures illustrate that while there is major research and development of biological pesticides, the numbers progressing through the regulatory system have not been great. This is in line with overseas trends where it has been reported that biological pesticides comprise $0.45 \%$ of the world agrochemical market (Powell and Jutsum 1993). There are a number of reasons for their slow development:

a Production-biological pesticides can be costly to produce, particularly those that can 
only be rearedin vivo, such as viruses. Production can be problematic, for example the production of the bacterium used in Invade for grass grub control was disrupted by bacteriophage infection, requiring the development of a phage resistant strain (Jackson et al. 1991).

b Slow control - a biological pesticide that is slow to control a pest, may not prevent damage and therefore affect the price the grower can obtain for his crop. For example Madex, containing codling moth granulosis virus, does not stop the caterpillars from feeding on apples once infected.

c Lack of persistence - while an advantage from a residue and public perception pointof-view, lack of persistence can be a disadvantage. Bacillus thuringiensis (Bt) products generally have poor persistence and therefore require more intensive use to maintain acceptable level of pest control compared to more persistent materials.

d Regulatory requirements - it was noted when the New Zealand guidelines on registration requirements were being developed that some health and safety requirements may be a barrier to registration from a cost point-of-view. While these are less of a problem for biological pesticides developed overseas, New Zealand has limited facilities and resources with which to undertake toxicological testing. During the development of Invade (Jackson et al. 1991), there were initial problems in identifying organisations capable of conducting the required toxicological testing. While an organisation which was prepared to undertake the testing was eventually found, New Zealand still lags behind other countries with regard to Good Laboratory Practice etc. The guidelines are now 15 years old and it may be appropriate to review them, as over this period a large data base of knowledge on biological pesticides has been collected. A review may find the current guidelines to be too stringent in light of recent knowledge, particularly in the area of safety testing.

e Useracceptance-users are concerned more about efficacy and cost than environmental issues (Agrow 1997). For example, growers used $B t$ for Colorado potato beetle control because the pest had developed resistance to chemical pesticides. However, these growers were quick to switch to imidacloprid because it was more effective and easier to use (Agrow 1997). Bt applications require more scouting and accurate timing as the bacterium is active only against specific stages of the insect lifecycle, introducing additional cost factors (Agrow 1997). Therefore, user education on the benefits of biological pesticides requires more promotion.

A number of these 'barriers' were reported in the OECD report on Registration of Biopesticides (Paris in 1994). However, it should be stressed that these 'barriers' to product development are offset against the many benefits which are stated widely in literature. However, companies should be cognisant of the 'barriers' when developing biological pesticides. Market share of most biological pesticides appears to be in niche markets at this stage. Their expansion will depend on a number of factors particularly overcoming the 'barriers' above.

\section{CONCLUSION}

Biological pesticides require registration under the Pesticides Act 1979 and the data requirements for their registration differ from chemical-based pesticides. Biological pesticides should not be considered a panacea to the pest problems of the world. Rather they are one of the many management tools available to users and alike in the agricultural and horticultural sector. Their success will depend largely on grower acceptance (whether it is environmental and/or cost benefit), market access and the regulatory level of control placed on them.

\section{REFERENCES}

Agrow, 1997. No 274 February 14. Pp 18-19. PJB Publications Ltd.

Jackson, T.A., Pearson, J.F., O'Callaghan, M., Mahanty, H.K. and Willocks, M.J., 1991. Pathogen to product - development of Serratia entomophila as a commercial biological control agent for the New Zealand Grass Grub. Pp 191-198. In: Use of Pathogens in Scarab Pest Management, T.A. Jackson and T.R. Glare (Eds), Intercept. 
OECD Environment Directorate, 14 November 1994, Pesticide Forum, Registration of Biopesticides.

Pesticides Section, 1984. Guidelines for the Registration of Biological Pesticides.

Powell, K.A. and Jutsum, A.R., 1993. Technical and commercial aspects of biocontrol products. J. Pesticide Sci. 37: 315-321. 